\title{
Cell-specific transmembrane injection of molecular cargo with gold nanoparticle-generated transient plasmonic nanobubbles
}

\author{
Ekaterina Y. Lukianova-Hleb ${ }^{1}$, Daniel S. Wagner ${ }^{1}$, Malcolm K. Brenner ${ }^{2}$, and Dmitri O. \\ Lapotko ${ }^{1,3,1}$ \\ ${ }^{1}$ Department of Biochemistry and Cell Biology, Rice University, Houston, 77005, TX, USA \\ ${ }^{2}$ Center for Cell and Gene Therapy, Baylor College of Medicine, The Methodist Hospital and \\ Texas Children's Hospital, Houston, 77030, TX, USA
}

${ }^{3}$ Department of Physics and Astronomy, Rice University, Houston, 77005, TX, USA

\begin{abstract}
Optimal cell therapies require efficient, selective and rapid delivery of molecular cargo into target cells without compromising their viability. Achieving these goals ex vivo in bulk heterogeneous multi-cell systems such as human grafts is impeded by low selectivity and speed of cargo delivery and by significant damage to target and non-target cells. We have developed a cell level approach for selective and guided trans-membrane injection of extracellular cargo into specific target cells using transient plasmonic nanobubbles (PNB) as cell-specific nano-injectors. As a technical platform for this method we developed a laser flow cell processing system. The PNB injection method and flow system were tested in heterogeneous cell suspensions of target and non-target cells for delivery of Dextran-FITC dye into squamous cell carcinoma HN31 cells and transfection of human T-cells with a green fluorescent protein-encoding plasmid. In both models the method demonstrated single cell type selectivity, high efficacy of delivery (96\% both for HN31 cells Tcells), speed of delivery (nanoseconds) and viability of treated target cells (96\% for HN31 cells and $75 \%$ for T-cells). The PNB injection method may therefore be beneficial for real time processing of human grafts without removal of physiologically important cells.
\end{abstract}

\section{Keywords}

DNA; gene transfer; laser; gold; nanoparticle

\section{Introduction}

Selective and efficient intracellular delivery of molecular cargo such as drugs, diagnostic and genetic agents into specific target cells determines the success of cell-based therapeutics. However, this function is impeded by cell defense systems and by limited efficacy, speed, selectivity and safety of various delivery technologies, especially in heterogeneous tissues where target cells are mixed with non-target cells and tissues. There

\footnotetext{
(C) 2012 Elsevier Ltd. All rights reserved.

${ }^{1}$ Department of Biochemistry and Cell Biology, Rice University, 6100 Main, MS-140, Houston, TX, 77005, USA, Tel.: 713-348-3708, Fax: 713-348-5154, d15@ rice.edu.
}

Publisher's Disclaimer: This is a PDF file of an unedited manuscript that has been accepted for publication. As a service to our customers we are providing this early version of the manuscript. The manuscript will undergo copyediting, typesetting, and review of the resulting proof before it is published in its final citable form. Please note that during the production process errors may be discovered which could affect the content, and all legal disclaimers that apply to the journal pertain. 
are two major approaches to intracellular delivery: specific targeting of the vehicles that carry the linked or encapsulated cargo, and modification of the permeability of cellular membranes during their exposure to extracellular cargo.

The greatest selectivity and efficacy of delivery has been achieved using nanoparticles (NP) as carriers and as mediators of the cargo release [1-5]. However, in heterogeneous cell systems the selectivity of NP targeting is limited by the unavoidable coupling of NPs to nontarget cells and dependence upon a release mechanism whose selectivity and activation are also limited. NP based delivery (like any delivery platform) requires linking or encapsulating the cargo, which may fail to isolate it from the environment, potentially leading to bystander-cell toxicity. The encapsulation of toxic cargo may reduce non-specific toxicity [6], but at the same time limits cargo release at the destination to rates determined by slow diffusion and does not address the problem of selective intracellular release of cargo. Several methods have been developed for on-demand release of encapsulated cargo with laser radiation [2, 3, 6-8] but all require the use of complex liposome-like NPs with cargo and gold NPs, which are difficult to synthesize, must be engineered for each application, and can be unstable in vivo. Moreover, their unavoidable non-specific uptake by normal cells reduces the selectivity of the delivery.

Extracellular molecular cargo can also be delivered following non-specific permeabilization of cell membranes with mechanical, electrical or thermal impacts [9-12] but these methods cannot discriminate between target and by-stander cells in a heterogeneous population. Furthermore, these methods do not actively deliver the cargo into cells, they just allow passive delivery due to the gradient of the cargo concentration outside and inside the cell. Hence, delivery is slow and the amount of cargo delivered cannot be precisely controlled other than by varying its extracellular concentration.

Active delivery may be produced using direct micro-injection [13], ballistic delivery [14] and laser nano-surgery of target cells $[15,16]$. Micro-injection and laser nano-surgery methods provide single cell selectivity but require precise manipulation of individual cells and cannot treat large numbers of cells in a heterogeneous system. Ballistic particle delivery is limited by shallow penetration of the cargo into the tissue, and by physical damage to samples. Thus, intracellular delivery into those cells has not been feasible unless individual target cells are first isolated, and this lack of a fast, selective and efficient means of effecting intracellular delivery of extracellular molecular cargo remains a principal challenge to gene and cell therapies.

We have overcome the above limitations by developing a new class of nano-agents which are not NPs but transient vapor nanobubbles, named plasmonic nanobubbles (PNBs) [17, 18 ] and generated with short laser pulses around cell-specific clusters of gold NPs that convert optical to thermal energy through the mechanism of plasmon resonance. Heat is locally released by NPs and evaporates their liquid nanoenvironment thus generating a PNB. Such vapor nanobubbles use thermal energy generated by gold NPs through the mechanism of plasmon resonance [19] and this thermal energy determines maximal diameter and lifetime of PNB and is controlled through the fluence of the laser pulse $[17,18]$. Fast adiabatic expansion of the PNB provides efficient thermal insulation of its environment from internal heat $[18,20]$. The mechanism we describe also explains the origin of the term "plasmonic nanobubbles": such vapor bubbles get their energy through plasmon resonance of gold NPs and act at the nanoscale as mechanical, optical and acoustic nano-agents. In particular, we discovered that the threshold energy of the laser pulse required to generate PNB rapidly decreases with the size of the NP cluster. This allows for the selective generation of PNBs at minimal and biologically safe optical energies around the largest clusters of NPs (selectively formed in target cells through the receptor-mediated endocytosis 
$[21,22])$, while preventing the generation of PNBs around smaller clusters and single NPs in non-target cells exposed to the same optical energy [17, 18, 23, 24]. This mechanism provides the principal advantage of PNBs compared to conventional NP-based methods: superior cellular selectivity of PNBs. Cellular applications of PNBs showed their two-fold function: localized mechanical, non-thermal, tunable and selective nature for destruction of target cells and optical scattering and acoustic emission for highly sensitive imaging of target cells and guidance of their destruction [21, 25]. Using the localized mechanical effects of PNBs, we demonstrated fast and efficient release of molecular cargo from individual liposomes [23] and cell-specific and non-invasive intracellular delivery of genetic cargo [24] in a single laser pulse procedures.

We hypothesized that target cell-specific intracellular delivery of the molecular cargo in heterogeneous cell system can be realized through a safe and fast simultaneous treatment of all cells, both targeted and non-target, with gold NP conjugates and a single short laser pulse. The selective formation in target cells of the clusters of gold NPs (Fig. 1a,b) will allow the generation of PNB (Fig. 1c) that will create a transient and reversible small nanohole in a cellular membrane (Fig. 1d) and an inbound jet [26, 27] (Fig. 1e). This nanojet will inject the extracellular media with its molecular cargo into the cytoplasm. This is a form of active delivery that employs localized and fast fluidic-flow instead of slow diffusion. The small and controllable size of PNBs will allow injection without destroying the cells. We developed our approach by elucidating the mechanism of molecular injection to specific cells (using a fluorescent dye as a cargo), prototyping the high-throughput flow system for cell processing and by applying the developed methods and system to transfection of human T-cells with a DNA plasmid.

\section{Methods and Materials}

\subsection{Cells models and their targeting}

2.1.1 Suspension model: human peripheral blood mononuclear cells-PBMC (peripheral blood mononuclear cells) were isolated from buffy coats (obtained from the Gulf Coast Blood Center, Houston TX), by ficoll gradient. CD3-positive T cells were enriched from PBMC using a Pan T cell Isolation Kit II (Miltenyi Biotec, Inc., Auburn, CA), and CD3-negative cells were enriched by depletion of CD3-positive cells from PBMC using CD3 microbeads (Miltenyi Biotec, Inc., Auburn, CA) according to the manufacturer's instructions. CD3-positive (target) and CD3-negative (non-target) cells were incubated at $5^{*} 10^{6}$ cells $/ \mathrm{ml}$ with $60 \mathrm{~nm}$ gold spheres conjugated by BioAssayWorks LLC (Ijamsville, MD) with target-specific antibody OKT3 for $30 \mathrm{~min}$ at $37^{\circ} \mathrm{C}, 5 \% \mathrm{CO}_{2}$, washed three times with media, and resuspended in phenol red-free RPMI with 10\% FBS. This provided the formation of NP clusters. Only target cells accumulate sufficient amount of gold NPs to assemble the largest clusters (for example, through the mechanism of receptor-mediated endocytosis) that will generate PNBs under the minimal optical energy supplied by the pump laser pulse. At the same time, unavoidable non-specific coupling of NPs to normal cells will result in much lower NP loads that will be insufficient to generate PNB. FITCDextran dye $(2 \mathrm{mg} / \mathrm{ml}$, mol wt $10 \mathrm{kDa})$ or a Green Fluorescent Protein-encoding plasmid (pIRII-I-eGFP, $50 \mu \mathrm{g} / \mathrm{ml}$ ) were added to samples just prior to laser scan or flow treatment. After completion of the PNB treatment, cells were washed three times with media, and incubated in RPMI with $10 \% \mathrm{FBS}$ and $5 \mathrm{ng} / \mathrm{ml} \mathrm{IL}-15$ at $37^{\circ} \mathrm{C}, 5 \% \mathrm{CO}_{2}$ and analyzed at the indicated time points. The living cells were assayed with a laser confocal microscopy (LSM-710, Carl Zeiss MicroImaging GmbH, Germany) in the bright field, optical scattering (for NP uptake analysis and imaging of NP clusters) and two fluorescent (FITC-Dextran or GFP) modes. 
2.1.2 Adherent model-We used HN31 squamous carcinoma cells (target cells associated with head and neck cancers) expressing epidermal growth factor receptor (EGFR) and immortalized normal human oral keratinocyte NOM9 cells (in the capacity of non-target cells). The NOM9 cells were cultured in KGM Complete Medium (Lonza Houston Inc., Houston, TX) at $37^{\circ} \mathrm{C}, 5 \% \mathrm{CO}_{2}$. Co-culture of $\mathrm{HN} 31$ and NOM9 cells was prepared by mixing cells in 1:1 ratio and seeded at a concentration of $700,000 \mathrm{cells} / \mathrm{ml}$ in a $\mu$-Slide VI (Ibidi LLC, Martinsried, Germany). Prior to mixing target and non-target cells we labeled target (HN31) cells with CellTrace Calcein Red-Orange AM (C34851, Invitrogen Corporation, Carlsbad, CA; $1 \mathrm{~h}$ incubation with $5 \mu \mathrm{M}$ of dye) in order to identify individual target cells in heterogeneous sample and for monitoring the viability and integrity of individual cells after treatment with PNBs (see below). The Cell were incubated with $60 \mathrm{~nm}$ gold spheres conjugated with the target-specific antibody Panitumumab (BioAssayWorks LLC, Ijamsville, MD) for 24 hours at $37^{\circ} \mathrm{C}, 5 \% \mathrm{CO}_{2}$, and washed three times with media. Fluorescence dye (FITC-Dextran, $2 \mathrm{mg} / \mathrm{ml}$, mol wt $10 \mathrm{kDa}$ or $2 \mathrm{MDa}$ ) was added to samples just prior to PNB treatment and was washed three times with media after completion of the treatment. Living individual cells were assayed with a laser confocal microscopy (LSM-710, Carl Zeiss MicroImaging GmbH, Germany) in bright field, optical scattering (for analysis of NP uptake and imaging of intracellular NP clusters) and two fluorescent (for imaging of Calcein Red-Orange and FITC-Dextran) modes. For cell processing with the flow system, the cells were tripsinized after incubation with NPs.

\subsection{Generation and detection of plasmonic nanobubbles}

2.2.1 Generation and detection of PNBs-PNBs were generated by transient heating of gold NPs with single laser pulses to temperatures well above the evaporation threshold for the liquid environment of NPs. We employed a pulse of length $70 \mathrm{ps,} 532 \mathrm{~nm}$ (PL-2250, Ekspla, Vilnius, Lithuania) for heating spherical gold NPs with an optical absorbance spectrum maximum very close to the laser wavelength. In addition, a short duration of laser pulse maximized the efficacy of NP heating to prevent three negative processes: thermal loss through thermal diffusion [28], NP photodamage [29] and attenuation of incident optical pulse by the developing vapor bubble [30]. We used previously developed methods and experimental set-up [21] to generate, image, detect and quantify PNBs in individual cells through their optical scattering images and time-responses detected in parallel with two probe lasers. The shape of the time-response signal was specific and different for a heatingcooling effect without generation of PNB and for generation of PNB, while the duration of the PNB-specific response characterized the PNB lifetime. The maximal diameter of the PNB is proportional to the PNB lifetime [17, 18, 26, 31]. In addition, the excellent optical scattering properties of the PNB [18] were used for its imaging in cells with the second, pulsed probe beam $\left(576 \mathrm{~nm}, 70 \mathrm{ps}, 0.1 \mathrm{~mJ} / \mathrm{cm}^{2}\right)$. This beam was directed at the sample under high angle of incidence and with $10 \mathrm{~ns}$ delay relative to the excitation laser pulse. Thus only the light scattered by transient PNB was collected by the microscope objective (20x) and detected by the imaging device described above. The diameter of the pump (excitation) laser beam was $15 \mu \mathrm{m}$ for PNB generation in individual CD3-positive/negative cells and $260 \mu \mathrm{m}$ for PNB generation in monolayers of HN31/NOM9 cells in scanning mode with a covering area of several hundred cells. The fluence $\left(30-60 \mathrm{~mJ} / \mathrm{cm}^{2}\right)$ of each laser pulse was measured by registering its image and measuring the beam diameter at the sample plane with the imaging device (Luka, Andor Technology, Northern Ireland) and by measuring the pulse energy using a pulse energy meter (Ophir Optronics, Ltd., Israel). This scheme provided direct and precise measurements of the incident optical fluence at the cell plane for each excitation pulse. Operation of all hardware was controlled by PC through custom software modules developed using the LabView platform. 
2.2.2 Flow system for treatment of cells by PNBs-We developed a flow system that included a programmable syringe pump (NE-1000, New Era Pump Systems, Wantagh, NY) and an optically transparent micro-flow cuvette ( $\mu$-Slide VI by Ibidi LLC, Martinsried, Germany) having a cross-section $1.0 \times 0.4 \mathrm{~mm}$ and a length of $17 \mathrm{~mm}$. The programmable syringe pump provided cell flow through the cuvette at a specific speed $(190 \mu \mathrm{l} / \mathrm{min})$ that was matched to the repetition rate $(40 \mathrm{~Hz})$ and the diameter $(1 \mathrm{~mm})$ of the pulsed excitation laser beam. The laser pulse fluence was varied in the range of 30 to $60 \mathrm{~mJ} / \mathrm{cm}^{2}$ to provide PNB generation in target cells. Non-target cells were treated using the same laser pulse fluences. The broad excitation laser beam simultaneously irradiated about $1.2^{*} 10^{3}$ cells per pulse at a cell concentration of $3 * 10^{6} \mathrm{cell} / \mathrm{ml}$.

\subsection{Cell analysis}

2.3.1 Fluorescence imaging-For calibration of fluorescence signals as a function of FITC-Dextran dye concentration, the thin $(7.6 \mu \mathrm{m})$ layers of dye solution were prepared between two cover glasses. The dye concentration varied from 0.001 to $0.4 \mathrm{mg} / \mathrm{ml}$. The pixel image amplitude of fluorescence signals was obtained with a laser confocal microscopy (LSM-710, Carl Zeiss MicroImaging GmbH, Germany), and the calibration curves (for $10 \mathrm{kDa}$ and $2 \mathrm{MDa}$ Dextrans) were used to estimate the intracellular concentration of the injected dye.

We imaged individual living cells with bright field and fluorescent (FITC-Dextran dye or GFP) laser confocal microscopy. The pixel image amplitude of the fluorescence-specific signal was measured for individual cells (30-50) at $0,48,72$ and 96 hours after PNB generation. The cells were considered as fluorescence-positive when the amplitude of fluorescence signals exceeded that in control samples: cells treated with dye/DNA plasmid and laser pulses alone. We measured the cell-averaged and maximal fluorescence pixel image amplitudes for each cell. The mean values of the pixel image amplitudes of each population were reduced by the level of the background signal.

2.3.2 Cell viability and concentration-The cell concentration and viability was tested for each sample before and after treatment of cell suspensions in the flow system. Two standard indicators were used for monitoring the viability of individual cells: Cell Trace Calcein Red AM and Trypan Blue. The first dye is well retained by live cells that possess intact plasma membranes, and consequently it is a useful fluorescent tracer and indicator of cell viability and integrity [32]. An advantage of the Calcein-based method compared to other fluorescent assays (such as MTT/MTS method) is its ability to monitor individual cells in real time, thus increasing the accuracy of viability measurements in heterogeneous cell systems (that were employed in this work). In addition, the Calcein-based method allowed us to monitor the integrity of the cell, i.e. the potential leakage of the cellular content during and after PNB treatment [33]. Fluorescence from Calcein Red AM was imaged and measured with a confocal laser microscope (LSM-710, Carl Zeiss MicroImaging GmbH, Germany). The mean pixel image amplitude of the fluorescent image was measured for individual cells and then averaged for the sub-population studied (50 cells in total). Cells were considered as Calcein Red AM-positive when their image pixel amplitude exceeded that of intact cells. The averaged values of the pixel image amplitudes of each subpopulation of cells were obtained prior and 2 hours after the PNB generation. The relative viability of target cells after PNB treatment was calculated as the concentration of Calcein Red AM-positive target cells before $\left(C_{0}\right)$ and after $\left(C_{l}\right)$ treatment: $R V=C / C_{1} * 100 \%$.

As an additional viability test, we used Trypan Blue staining for each cell sample before ( 0 h) and after (48, 72 and 96 h) PNB treatment. To evaluate the flow system, we used one complex parameter that combined the changes in cell concentration and viability, defined as 
the relative residual viability $(R R V)$ index and calculated from the level of cell viability and concentration: $R R V=C_{2} / C_{O}{ }^{*} V$, where $C_{2}$ is cell concentration after treatment, $C_{O}$ is the initial cell concentration before treatment, and $V$ is the viability of the cells measured after PNB treatment. For analysis of residual viability of target cells in heterogeneous samples of target and non-target cells, the target cells were labeled with Calcein Red Am and the cell concentration and viability were analyzed just for the Calcein Red AM-positive subpopulation.

\section{Results and Discussion}

\subsection{Nano-delivery of the molecular cargo into suspension and adherent cells}

To examine the ability of PNBs to introduce extracellular material into cells, we tested two models of likely targets of PNB injection-based treatments. The suspension model used CD3-positive human T-cells as the target cells and CD3-negative peripheral blood mononuclear cells as the non-target cells. The adherent model used the squamous cell carcinoma line HN31 as the target cells and the epithelial line NOM9 as non-target cells. In order to form gold NP clusters in target cells for selective generation of PNBs, both cell systems were incubated with $60 \mathrm{~nm}$ gold NPs (spheres) conjugated in each case with targetspecific antibody (OKT 3 for CD3-positive cells and Panitumumab for HN31 cells). Prior to mixing the target and non-target cells, we labeled the target cells with Calcein red vital dye in order to identify individual target cells and for monitoring the viability and integrity of individual cell in response to PNBs. Formation of gold NP clusters was directly monitored by confocal microscopy in scattering mode. After incubation of the cells with gold NP conjugates, the large NP clusters were observed in 99\% of target cells (Fig. 2a,e). Next, each cell sample was scanned with broad pulsed laser beam that provided a single pulse simultaneous irradiation of several hundred cells with a 70 ps pulse at the wavelength close to the maximal optical absorbance of gold NPs $(532 \mathrm{~nm})$. Generation of PNBs was monitored in real time for individual cells by time-resolved optical scattering imaging (Fig. 2b,f) and by optical-scattering time-response (Fig. 2d,h) whose shape allowed identification of the PNB in specific cells and whose duration allowed us to measure the PNB lifetime that characterized its maximal diameter [18, 26]. We observed PNBs mainly in target cells (Fig. 2b,d and Fig. 3a,d) while either no, or small PNBs were detected in non-target cells (Fig. $2 \mathrm{f}, \mathrm{h})$. PNB generation correlated well with the formation of the largest NP clusters. The selectivity of PNB generation exceeded the selectivity of the NP cluster formation due to the threshold requirement for PNB generation and the effect of reduced PNB threshold for large NP clusters (reported by us in detail previously [20,34]). For the purpose of the current study, we limited the PNB lifetime to a small, non-invasive level with a lifetime in the range from $20 \mathrm{~ns}$ to $100 \mathrm{~ns}$ in target cells (Fig. 3a,d), since this is below the lethal duration of 110170 ns $[21,35]$. The small PNBs required relatively low level of laser pulse fluence (Fig. $3 a, d)$ that was within the in vivo safety limits for the laser [36]. Hence, PNBs can be selectively generated in target cells and their maximal size (lifetime) can be tuned with the fluence of laser pulse.

After verifying the selectivity of NP-PNB targeting, both cell systems were exposed to single laser pulses of variable fluence in the presence of an extracellular molecular cargo, fluorescent dye (FITC) coupled to Dextran of variable molecular weight from $10 \mathrm{kDa}$ to 2 MDa representing a wide range of potential cargo sizes. After generating PNBs with a single laser pulse, the dye was immediately washed from the cells and the dye-specific fluorescence was imaged and measured in individual cells by confocal microscopy. In both suspension and adherent cells, the dye was detected mainly in target cells immediately after the PNB treatment (Fig. 2c,g and Fig. 3b,e). Within 10 min of PNB generation we observed highly localized fluorescent spots (Fig. 2c, insert) suggesting that the initial delivery was localized to such spots. Later scans showed more homogenous distribution of the 
fluorescence over the cell (Fig. 2c). We observed highly selective delivery of the dye into target cells, and the level of intracellular fluorescence was significantly higher in target cells than in non-target cells (Fig 3b,e). Furthermore the amount of cargo delivered could be controlled by varying laser fluence to regulate PNB size (Fig. 3g). In addition, we counted the level of the dye-positive target cells (percentage among target cells) as a function of PNB lifetime (Fig. 3c, f) and found a high efficacy of intracellular delivery that correlated to the PNB lifetime. Next, we measured the level of fluorescence of cargo solution as a function of its concentration and obtained calibration curves (not shown) with which we estimated the intracellular concentration of the injected dye (Fig. 3g, right Y axis). The intracellular concentration of injected dye correlated with the PNB size (lifetime), and was tunable through the size of PNB that, in turn, was controlled by the fluence of the pump laser pulse (Fig. 3a,b). The quantity of cargo delivered was significantly higher than the amount that can diffuse into a cell through an intact membrane over the same 30 min time period of the experiment. This can be clearly seen by comparing the level of fluorescence in PNB-positive and PNB-negative cells (Fig. 2c,f). Under identical PNB lifetimes adherent cells showed double the concentration of the delivered cargo compared to suspension cells (Fig. 3g). This can be explained by the different volumes of these cells even if the initially delivered amount of cargo was identical (Fig. 3g). The molecular weight of the cargo substantially influenced the intracellular concentration of the delivered cargo and hence the fluorescence: the concentration was 10-20 times lower for large molecules (2 MDa versus $10 \mathrm{kDa}$ ) under identical PNB lifetimes (Fig. 3g). Such difference can be attributed to the mechanism of the delivery that is discussed in detail below.

Viability and concentration of all cells were measured at $72 \mathrm{~h}$ after PNB generation and compared to the corresponding levels obtained before PNB treatment. We used one compound parameter defined as a relative residual viability $(R R V)$ index (see 2.3.2), which characterizes the relative decrease of the cell concentration due to cell lysis whilst also incorporating the viability of the residual cells. Thus the $R R V$ index allows us to monitor the change in the proportion of viable cells. The viability and $R R V$ index of target cells was measured as function of PNB lifetime (Fig. 3c,f). Both suspension and adherent target cells survived the generation of small PNBs. An increase of the PNB lifetime (size) caused a slight decrease in the $R R V$ index (suspension cells, Fig. 3c) and viability (adherent cells, Fig. 3f). Nevertheless, even for the largest PNBs, the levels of $R R V$ and viability were around $80 \%$ demonstrating the low toxicity of PNBs. Therefore, with a single pulse PNB treatment we achieved intracellular delivery that combined high efficacy, selectivity and safety for target cells.

The delivery of the cargo into the cells was associated with a one-time generation of PNBs (often even a single PNB was observed per cell) around intracellular clusters and showed a very rapid increase of the intracellular fluorescence in the spots that spatially coincided with PNBs (Fig. 2c, insert). Generation of the expanding and collapsing bubbles near cellular membranes was earlier found to cause disruption of membrane barrier function $[10,25,37$, 38]. Based on the results obtained, we made several estimates:

1. PNB transiently perforates a membrane (Fig. 1c-e) and the cell survives such localized disruption of the membrane. Maximal diameter of such transient nonlethal hole can be estimated by $1 \mu \mathrm{m}$ based on the previous studies $[16,39,40]$.

2. Knowing the volume of the cell and the intracellular concentration of the delivered cargo (Fig. 3g) we estimated the mass of delivered cargo;

3. Knowing the external concentration of the cargo and delivered mass we estimate the delivered volume of the extracellular cargo as $3-10 * 10^{-6} \mathrm{~nL}$; 
4. In the case of delivery from a single PNB of specific lifetime of 20-80 ns, the delivery rate is estimated at $40-500 \mathrm{~nL} / \mathrm{s}$ assuming that the process of the delivery coincides with PNB in time.

5. Such a delivery rate is too high to be explained by passive diffusion caused by the gradient concentration of the extracellular molecules through open, disrupted or stressed membrane. Using Ficks law [41], water diffusivity and $100 \mathrm{~nm}$ gradient we estimated that diffusion, even through an open hole, would deliver four orders of magnitude fewer external molecules into the cell. Therefore, the observed delivery effect requires active flow of extracellular liquid into the cell. Thus our results proved the direction (inbound) and the speed (above $10 \mathrm{~m} / \mathrm{s}$ ) of the flow associated with intracellular delivery.

6. Such a process can be defined as PNB-induced injection (Fig. 1e).

Emergence of the inbound transient nano-jet can be explained by asymmetrical expansion and collapse of the PNB. A similar effect was previously observed at micro and macro-scale for thermal and cavitation vapor bubbles [26, 27] (Fig. 1e). Our estimate of jet speed is also in line with the data obtained for bubble-induced jets $10^{1-2} \mathrm{~m} / \mathrm{s}$ [27]. Due to the nano-size of PNB and the brief lifetime of the jet, it is technically impossible to image the jet in the presence of a highly fluorescent extracellular dye. For an intracellular PNB, the jet can be pointed to the center of the bubble (i.e. inside the cell) and opposite to the membrane, similar to cavitation-induced bubble jets $[42,43]$.

Hence, selective generation of small non-invasive PNBs in target cells induces a PNBnanojet that permits delivery of a cargo in a way that is tunable, rapid, cell type specific and of low toxicity. This method can be easily adapted to automated systems that will provide specific drug or gene delivery through feedback of PNB generation and size of the resulting PNB. In the experiments described above, we detected PNBs in a real time with two independent techniques, time-resolved scattering imaging (Fig. 2b) and scattering timeresponse (Fig. 2d). In each case PNBs indicated the successful intracellular delivery of the cargo into specific cells. Optical parameters of the PNBs correlated to the efficacy of the injection (Fig. 3c,g). Since PNBs were simultaneously detected in individual cells, they provided real time quantitative guidance of injection of the cargo with cell level resolution. Furthermore, since the PNB lifetime is determined by the energy (fluence) of the excitation laser pulse (Fig. 3a,d), by monitoring PNB signals we can dynamically control the laser pulse fluence in order to provide the desired efficacy of injection. This possibility is illustrated in Figs. $3 \mathrm{~b}$ and e that show how the efficacy of the injection (shown as the level of the fluorescence of the injected cargo) can be controlled through the fluence of the excitation laser pulse. Therefore, the PNB method provides both real-time guidance and the opportunity for dynamic control of the injection process through a feedback loop that relates the detected PNB lifetime to the device that controls the fluence of the excitation laser pulse. All PNB - related signals are very short, below $10^{-7} \mathrm{~s}$ and can be rapidly communicated (via signal-processing software) to high-speed optical attenuators (like electro-optic shutters) for adjusting the fluence of the laser pulses in a real time. This option, in turn, suggests the possibility of high-speed laser treatment of the cells. Therefore, PNB injection can be performed under real time guidance that can automatically adapt the optical fluence excitation to variable conditions of PNB generation in heterogeneous cell systems.

\subsection{Flow processing of PNB mediated nano-injection}

The experimental set up employed for the above experiments cannot provide the rapid treatment of bulk quantities of cells $\left(10^{8-9}\right.$ cells) required for clinical therapies. We therefore developed a high-throughput PNB-based injection, using flow technology. In this approach, NP-pretreated heterogeneous suspension of cells are passed through an optically transparent 
cuvette and exposed to pump laser pulses (Fig. 4). The flow rate, dimensions of the cuvette and the diameter and repetition rate of the excitation laser can be combined to provide simultaneous exposure to a single excitation pulse of $>10^{3}$ cells.

Our prototype flow system included a programmable syringe pump and optically transparent micro-flow cuvette with a cross-section $1.0 \times 0.4 \mathrm{~mm}$ and a length of $17 \mathrm{~mm}$ (Fig. 4). The programmable syringe pump provide cell flow through the cuvette at $1 \mathrm{~cm} / \mathrm{s}$, a rate matched to the laser repetition rate $(40 \mathrm{~Hz})$ and the diameter $(1 \mathrm{~mm})$ of the pulsed excitation laser beam. This slow speed provided less sheer stress for living cells compared to commercial flow cytometers and sorters (>10 m/s). The broad excitation laser beam simultaneously irradiated about $1.2 * 10^{3}$ cells per pulse for a cell concentration of $3 * 10^{6}$ cell $/ \mathrm{ml}$. This combination of cell concentration, flow rate and laser repetition rate provide the cell processing rate of $5^{*} 10^{4}$ cell/s to be processed that was sufficient for testing the PNB method for the efficacy and selectivity of the injection.

We prepared a suspension of HN31 (target) and NOM9 (non-target) cells that were targeted with gold NP-Panitumumab conjugates as described above. Prior to seeding the cells, we stained the target cells with the vital fluorescent dye Calcein Red AM that provided three functions: identified the target cells in heterogeneous suspension, monitored their viability and integrity (leakage) in response to PNB. After NP treatment and tripsinization of cells, FITC-Dextran $(10 \mathrm{kDa})$ was added to the suspension at $2 \mathrm{mg} / \mathrm{ml}$ as extracellular molecular cargo. Target cells were analyzed prior to flow treatment to determine the initial concentration of Calcein Red AM-positive cells and the level of fluorescence amplitude in target cells (Fig. 5a, d). Then the cells were treated with PNBs in the flow system at a level of excitation fluence that produced PNBs with an average lifetime of $91 \pm 13$ ns that was found to be safe for the target cell (Fig. 3f). The collected cells were washed to remove external FITC-Dextran and then were analyzed for the second time by confocal laser microscope to identify target cells and measure their viability and integrity (through Calcein red fluorescence, Fig. 5c), to determine the efficacy and selectivity of NP targeting (through optical scattering of NPs) and the selectivity and efficacy of the injection of extracellular FITC-Dextran (through green FITC-specific fluorescence, Fig. 5b). FITC-specific green fluorescence indicated the FITC-Dextran was delivered into the cells after a single pulse flow treatment (Fig. 5b). We observed FITC-positive fluorescence in $96 \% \pm 6$ of Calcein Red AM-positive cells, indicating high efficacy delivery of Dextran-FITC into target HN31 cells that was in line with previous static experiments with the same cells, in which the efficacy of delivery was about $98 \%$ (Fig. 2f). We also observed excellent correlation between FITCpositive cells (green signal), target cells (red signal) and the cells with large NP clusters (scattering signal). The mean intracellular level of FITC fluorescence in target cells increased from $83 \pm 25$ counts before treatment to $16600 \pm 2030$ counts 10-20 min after the treatment (Fig. 5 b,d), while in non-target cells the post-treatment fluorescence of FITCDextran changed little, remaining at $113 \pm 23$ counts (more than two orders of magnitude less that in target cells). These data show high efficacy and high selectivity of the injection of the Dextran cargo in flow mode.

Calcein Red-specific fluorescence was additionally used to monitor the viability and integrity of target cells in response to the PNB treatment. The relative viability was determined for the treated target cells by comparing the concentrations of Calcein Redpositive cells before and after the treatment described in section 2.3.2. The concentrations of Calcein Red-positive cells in suspension were $49 \%$ before treatment and $48 \% 2 \mathrm{~h}$ after the PNB treatment or $96 \%$ relative viability of target cells (Fig. 5d). The cell-averaged values of the pixel image amplitudes of Calcein Red fluorescence were then compared for untreated target cells (Fig. 5a) and $2 \mathrm{~h}$ after the PNB flow treatment (Fig. 5c). The amplitude of Calcein Red AM-specific fluorescence remained essentially unchanged (Fig. 5d). Therefore, 
target cells retained relatively high short-term viability after the flow PNB treatment and did not lose detectable amounts of molecular content due to leakage associated with PNBinduced disruption of cellular membranes. The observed high level of cell integrity is also in line with the injection mechanism discussed above: the transient nature of PNB-induced hole in the membrane, its small diameter and the presence of the inbound flow all serve to prevent leakage of intracellular contents.

In addition to the Calcein Red-based method we used Trypan Blue exclusion with Calcein Red-positive cells at the same time points (Fig. 5d). In this case counts were performed only within target (i.e. Calcein Red-positive) cells and they showed levels of target cell viability at $98 \%$ before PNB treatment and $94 \% 2 \mathrm{~h}$ after the treatment. These data are in good agreement with the viability data obtained from Calcein Red AM fluorescence (Fig. 5d). We therefore concluded that Trypan Blue is sufficiently accurate to assess the short-term effects of PNB on cell viability.

This experiment demonstrated the feasibility of combining PNB-based injection of extracellular molecular cargo with flow multi-cell treatment technology. Such combination may significantly improve cell processing in some clinical applications such as gene therapy, autologous bone marrow transplantation or other ex vivo treatments that may require selective and fast treatment of as many as $10^{9-10}$ cells. Maintaining the viability of these grafts and ensuring scalability of the approach to high patient volumes, requires that all manipulations must be performed as rapidly as possible. In addition to a sample preparation time of 30-40 min for incubating with gold NPs, subsequent processing time should ideally be $<20 \mathrm{~min}$. No existing technologies can provide such a processing rate together with a single cell selectivity of processing. By contrast, our flow PNB technology demonstrated a single cell type selectivity with a processing rate of about $5 * 10^{4}$ cell/s, which can readily be increased to $10^{8}$ cell/s by employing a higher repetition rate excitation laser (up to $5 \mathrm{kHz}$ ) and increasing the laser energy to increase the beam diameter and increasing the cell concentration to $10^{7} \mathrm{cell} / \mathrm{ml}$.

\subsection{Gene transfer into human T-cells with flow system}

Delivery of gene therapy to specific cells in a mixed population will form the basis of diverse therapies. To test the efficacy of cell targeting in complex cell mixtures of clinical relevance we applied the PNB flow method for cell-specific delivery of a DNA plasmid encoding a CMV promoter driving expression of enhanced Green Fluorescent Protein (eGFP) into human T-cells surrounded by non-target cells. This experiment was intended as proof-of-principle with the focus on the selectivity and efficacy of the delivery of molecular cargo into specific cells in a heterogeneous cell system. Peripheral blood T cells are positive for the marker CD3 and we mixed these cells with CD3 negative by-stander cells (PBMC) and incubated them with $60 \mathrm{~nm}$ solid gold spheres conjugated to CD3 monoclonal antibody (OKT3). Plasmid pIRII-I-eGFP was added into the mixed suspension of cells prior to flow treatment at $50 \mu \mathrm{g} / \mathrm{ml}$. Cells were exposed to a single laser pulse $(70 \mathrm{ps}, 532 \mathrm{~nm})$ in the flow cuvette, at a reduced specific fluence $\left(20-45 \mathrm{~mJ} / \mathrm{cm}^{2}\right)$ that enabled the generation of small PNBs with a size between $20 \mathrm{~ns}$ and $100 \mathrm{~ns}$ (Fig. 6a). PNBs were observed mainly in target cells (Fig. 6b,e, Fig. 7a). The level of GFP expression was measured at $48 \mathrm{hr}, 72 \mathrm{hr}$ and 96 hr. Wide-field fluorescent images of the mixed cell suspensions before (Fig. $6 \mathrm{~g}$ ) and after 48 $\mathrm{h}$ of PNB treatment (Fig. 6h) indicated successful transfection, and GFP expression was observed mainly in CD3-positive cells (up to $96 \%$ positive after a single pulse flow treatment procedure) over the whole range of optical excitation fluences (Fig. 6c,f, Fig. 7b), indicating high efficiency of gene transfection. Specificity of transfection is indicated by the low rate of transfection of non-target cells (10\%, Table 1). In future applications, this off target effect may be further decreased by the use of cell type-specific promoters to drive expression only in target cells. In addition, we observed a direct correlation between the 
PNB size (lifetime) and eGFP-specific fluorescence. Only PNB-treated cells exhibited significant and selective increase of eGFP-specific fluorescence while the same cells treated only with DNA plasmid or only with a laser pulse (in the absence of gold NPs) lacked any significant increase in fluorescence (Fig. 7 d). Our interpretation was that PNBs selectively injected plasmid DNA into CD3-positive target cells. Consistent with this assessment, when we removed the plasmid immediately after the PNB treatment, the level of GFP fluorescence in target cells remained the same as in the previous experiment in which the plasmid was present in cell suspension for 72 hours. A high efficacy of gene transfer was achieved with acceptable levels of cell viability as the $R R V$ index measured in $72 \mathrm{~h}$ after the injection of plasmid (Fig. 7c, Table 1). The decrease of that index was mainly caused by the decrease in cell concentration.

\subsection{PBNs vs other methods of molecular delivery and transfection}

Current approaches use various effects of external energy, such as sono-, electro- and optoporation $[9,10-12]$ and targeted carriers $[6,44,45]$. Highest precision of the delivery was achieved with laser methods [40] which employ several laser-induced processes: heating [46], shockwave generation [47] and plasma formation during optical breakdown [15, 16, $26,48]$. Femtosecond laser pulse-induced optical breakdown was shown to be a very precise tool for non-invasive injection into individual cells [16, 26, 39, 49] but cannot be applied simultaneously to many heterogeneous cells and requires the precise positioning of the laser beam on a target cell. Other optical methods have been applied in vivo [50, 51] but they also required the focusing of the laser beam onto a single cell (rather than the wide field application we show here) and thus cannot process clinical samples with many different cells within reasonable time. Some of those methods also use laser-induced vapor bubbles [52-55] but these are all extracellular macro-bubbles, much larger than the cell itself. Moreover, because these bubbles are generated in extracellular space and are not associated with specific target cells, they cannot provide any selectivity. All above physical methods of perforating cells only allow delivery by diffusion down a concentration gradient of molecular cargo through a restrictive opening in cellular membrane. This process is quite slow and results in long incubation time and slow processing speed. Contrary, active inflow of cargo via a high speed nano-jet induced by a PNB rapidly brings a volume of extracellular cargo inside the restrictive opening in the cell membrane allowing high speed of cell processing. When applied to mixtures of multiple cells, however, all methods cited above cannot discriminate between target and by-stander cells in a heterogeneous population because they all apply untargeted impacts that perforate or permeate equally the membranes of target and non-target cells.

Gold NPs targeted to specific cells have been used as local converters of light to heat and their photothermal effect employed to improve the selectivity of gene transfer [55]. However, the physical mechanisms of such transfer so far remain uncontrollable (partly because of lack of real-time guidance). Furthermore, the non-threshold thermal effects of gold NPs lack selectivity due to non-specific uptake of gold NPs by non-target cells and due to uncontrollable thermal diffusion from heated NPs. Other NP-based approaches for targeted gene transfection used liposomes, dendrimers or PEI (polyethyleneimine) NPs (usually conjugated to a specific vector for active targeting) as carriers of DNA plasmids. This improved the efficacy of gene delivery to 40-70\% for actively targeted PEI-NPs [44], up to $85 \%$ for dendrimer NPs and up to $52 \%$ for Lipotap liposomes in combination with gold NPs for enhanced targeting. Cytotoxicity of the above NP-based methods was reduced with viability of the target cells at 5-50\% for PEI-NPs [44], 70-90\% for dendrimers [44], and $69-91 \%$ for liposome-gold NP complexes. Despite apparent improvements in the efficacy and viability of the above NP-based methods (compared to methods based on free extracellular solution of DNA plasmid), the selectivity of any NP-based method is 
principally limited by unavoidable non-specific uptake of NPs by non-target cells even when active targeting is used with target-specific vectors. PNB overcomes this limitation by the PNB-specific NP cluster-threshold mechanism of PNB generation (see also 2.2.1). Fast and direct injection of the cargo into the cellular cytoplasm should also reduce the dependence of the transfection efficacy of the PNB method upon many biological parameters, such signaling and transcription factors [56] that are critical on many current methods of gene transfection. Thus the PNB injection mechanism improves the efficacy, processing rate and reduces the toxicity of the delivery procedure. Thus for heterogeneous mixtures of cells requiring high selectivity of delivery, PNB provide the best combination of viability, efficacy, selectivity and speed compared to other existing delivery technologies.

\section{Conclusions}

We developed a method and prototype of a cell processing flow system that provides fast, cell-specific, efficient and guided intracellular delivery of molecular cargo to individual target cells in heterogeneous cell suspensions. The mechanism of the injection employs highly localized and transient injection effect of cell-specific plasmonic nanobubble. This injection mechanism significantly differs from previous optical- and nanoparticle-based methods of the delivery by providing high selectivity, speed, efficacy and viability and represents an entirely new approach that combines active injection, cell level localized mechanism and real time guidance. Thus PNB nano-injection has the potential to revolutionize drug delivery and gene therapy in diverse applications.

\section{Acknowledgments}

Authors thank Drs. Xiangwei Wu and Xiaoyang Ren of the UT MD Anderson Cancer Center and Dr. Leslie E. Huye of Center for Cell and Gene Therapy, Baylor College of Medicine, The Methodist Hospital and Texas Children's Hospital (Houston, TX) for their help with preparation and characterization of cell samples. This work was supported in part by National Institute of Health Grant R01GM094816. Confocal microscopy was performed on equipment obtained through a Shared Instrumentation Grant from the National Institutes of Health (S10RR026399-01).

\section{References}

1. Gaspar VM, Correia IJ, Sousa A, Silva F, Paquete CM, Queiroz JA, et al. Nanoparticle mediated delivery of pure P53 supercoiled plasmid DNA for gene therapy. J Control Release. 2011; 156:212222. [PubMed: 21864596]

2. Peer D, Karp JM, Hong S, Farokhzad OC, Margalit R, Langer R. Nanocarriers as an emerging platform for cancer therapy. Nat Nanotechnol. 2007; 2:751-760. [PubMed: 18654426]

3. Sajja HK, East MP, Mao H, Wang YA, Nie S, et al. Development of multifunctional nanoparticles for targeted drug delivery and noninvasive imaging of therapeutic effect. Curr Drug Discov Technol. 2009; 6:43-51. [PubMed: 19275541]

4. Duncan B, Kim C, Rotello VM. Gold nanoparticle platforms as drug and biomacromolecule delivery systems. J Control Release. 2010; 148:122-127. [PubMed: 20547192]

5. Braun GB, Pallaoro A, Wu G, Missirlis D, Zasadzinski JA, Tirrell M, et al. Laser-activated gene silencing via gold nanoshell-siRNA conjugates. ACS Nano. 2009; 3:2007-2015. [PubMed: 19527019]

6. Musacchio T, Torchilin VP. Recent developments in lipid-based pharmaceutical nanocarriers. Front Biosci. 2011; 16:1388-1412. [PubMed: 21196238]

7. Qin G, Li Z, Xia R, Li F, O'Neill BE, Goodwin JT, et al. Partially polymerized liposomes: stable against leakage yet capable of instantaneous release for remote controlled drug delivery. Nanotechnology. 2011; 22:155605. [PubMed: 21389566]

8. Torchilin VP. Targeted pharmaceutical nanocarriers for cancer therapy and imaging. AAPS J. 2007; 9:E128-E147. [PubMed: 17614355] 
9. Fechheimer M, Boylan JF, Parker S, Sisken JE, Patel GL, Zimmer SG. Transfection of mammalian cells with plasmid DNA by scrape loading and sonication loading. Proc Natl Acad Sci USA. 1987; 84:8463-8467. [PubMed: 2446324]

10. Prentice P, Cuschierp A, Dholakia K, Prausnitz M, Campbell P. Membrane disruption by optically controlled microbubble cavitation. Nat Phys. 2005; 1:107-110.

11. Lee S, McAuliffe DJ, Flotte TJ, Kollias N, Doukas AG. Photomechanical transcutaneous delivery of macromolecules. J Invest Dermatol. 1998; 111:925-929. [PubMed: 9856797]

12. Choi Y, Yuen C, Maiti SN, Olivares S, Gibbons H, Huls H, et al. A high throughput microelectroporation device to introduce a chimeric antigen receptor to redirect the specificity of human T cells. Biomed Microdevices. 2010; 12:855-863. [PubMed: 20574820]

13. Kim TK, Eberwine JH. Mammalian cell transfection: the present and the future. Anal Bioanal Chem. 2010; 397:3173-3178. [PubMed: 20549496]

14. Muangmoonchai R, Wong SC, Smirlis D, Phillips IR, Shephard EA. Transfection of liver in vivo by biolistic particle delivery - Its use in the investigation of cytochrome P450 gene regulation. Mol Biotechnol. 2002; 20:145-151. [PubMed: 11876471]

15. Soughayer JS, Krasieva T, Jacobson SC, Ramsey JM, Tromberg BJ, Allbritton NL. Characterization of cellular optoporation with distance. Anal Chem. 2000; 72:1342-1347. [PubMed: 10740880]

16. Stevenson D, Agate B, Tsampoula X, Fischer P, Brown CTA, Sibbett W, et al. Femtosecond optical transfection of cells: viability and efficiency. Opt Express. 2006; 14:7125-7133. [PubMed: 19529083]

17. Lukianova-Hleb E, Lapotko DO. Influence of transient environmental photothermal effects on optical scattering by gold nanoparticles. Nano Lett. 2009; 9:2160-2166. [PubMed: 19374436]

18. Lukianova-Hleb E, Hu Y, Latterini L, Tarpani L, Lee S, Drezek RA, Hafner JH, Lapotko DO. Plasmonic nanobubbles as transient vapor nanobubbles generated around plasmonic nanoparticles. ACS Nano. 2010; 4:2109-2123. [PubMed: 20307085]

19. Hu M, Chen JY, Li ZY, Au L, Hartland GV, Li X, et al. Gold nanostructures: engineering their plasmonic properties for biomedical applications. Chem Soc Rev. 2006; 35:1084-1094. [PubMed: 17057837]

20. Lapotko D. Pulsed photothermal heating of the media during bubble generation around gold nanoparticles. Int J Heat Mass Tran. 2009; 52:1540-1543.

21. Wagner DS, Delk NA, Lukianova-Hleb EY, Hafner JH, Farach-Carson MC, Lapotko DO. The in vivo performance of plasmonic nanobubbles as cell theranostic agents in zebrafish hosting prostate cancer xenografts. Biomaterials. 2010; 31:7567-7574. [PubMed: 20630586]

22. Lapotko D, Lukianova-Hleb E, Oraevsky A. Clusterization of nanoparticles during their interaction with living cells. Nanomedicine. 2007; 2:241-2453. [PubMed: 17716124]

23. Anderson L, Hansen E, Lukianova-Hleb EY, Hafner JH, Lapotko DO. Optically guided controlled release from liposomes with tunable plasmonic nanobubbles. J Control Release. 2010; 144:151158. [PubMed: 20156498]

24. Lukianova-Hleb E, Samaniego A, Wen J, Metelitsa L, Chang C-C, Lapotko D. Selective gene transfection of individual cells in vitro with plasmonic nanobubbles. J Control Release. 2011; 152:286-293. [PubMed: 21315120]

25. Lapotko D, Lukianova E, Oraevsky A. Selective laser nano-thermolysis of human leukemia cells with microbubbles generated around clusters of gold nanoparticles. Lasers Surg Med. 2006; 38:631-642. [PubMed: 16736503]

26. Vogel A, Noack J, Huttman G, Paltauf G. Mechanisms of femtosecond laser nanosurgery of cells and tissues. Appl Phys B. 2005; 81:1015-1047.

27. Sankin GN, Yuan F, Zhong P. Pulsating tandem microbubble for localized and directional singlecell membrane poration. Phys Rev Lett. 2010; 105:078101. [PubMed: 20868077]

28. Anderson RR, Parrish JA. Selective photothermolysis: precise microsurgery by selective absorption of pulsed radiation. Science. 1983; 220:524-527. [PubMed: 6836297]

29. Hleb EY, Lapotko DO. Photothermal properties of gold nanoparticles under exposure to high optical energies. Nanotechnology. 2008; 19:355702. [PubMed: 21828856] 
30. François L, Mostafavi M, Belloni J, Delaire J. Optical limitation induced by gold clusters: mechanism and efficiency. Phys Chem. 2001; 3:4965-4971.

31. Rayleigh L. On the pressure developed in a liquid during the collapse of a spherical cavity. Philos Mag. 1917; 34:94-98.

32. Mueller H, Kassack MU, Wiese M. Comparison of the usefulness of the MTT, ATP, and calcein assays to predict the potency of cytotoxic agents in various human cancer cell lines. J Biomol Screen. 2004; 9:506-515. [PubMed: 15452337]

33. Denizot F, Lang R. Rapid colorimetric assay for cell growth and survival. Modifications to the tetrazolium dye procedure giving improved sensitivity and reliability. J Immunol Methods. 1986; 89:271-277. [PubMed: 3486233]

34. Lapotko D. Optical excitation and detection of vapor bubbles around plasmonic nanoparticles. Opt Express. 2009; 17:2538-2556. [PubMed: 19219157]

35. Lukianova-Hleb E, Hanna EY, Hafner JH, Lapotko DO. Tunable plasmonic nanobubbles for cell theranostics. Nanotechnology. 2010; 21:085102.

36. Laser Institute of America. American national standard for safe use of lasers (ANSI Z136.1-2000). 2000

37. Philipp A, Lauterborn W. Cavitation erosion by single laser-produced bubbles. J Fluid Mech. 1998; 361:75-116.

38. Sundaram J, Mellein BR, Mitragotri S. An experimental and theoretical analysis of ultrasoundinduced permeabilization of cell membranes. Biophys J. 2003; 84:3087-3101. [PubMed: 12719239]

39. Kohli V, Acker JP, Elezzabi AY. Reversible permeabilization using high-intensity femtosecond laser pulses: applications to biopreservation. Biotechnol Bioeng. 2005; 92:889-899. [PubMed: 16189821]

40. Tsukakoshi M, Kurata S, Nomiya Y, Ikawa Y, Kasuya T. A novel method of DNA transfection by laser microbeam cell surgery. Appl Phys B. 1984; 35:135-140.

41. Eisenberg, D.; Kauzmann, W. The structure and properties of water. London: Oxford University Press; 1969.

42. Fong SW, Klaseboer E, Turangan CK, Khoo BC, Hung KC. Numerical analysis of a gas bubble near bio-materials in an ultrasound field. Ultrasound Med Biol. 2006; 32:925-942. [PubMed: 16785014]

43. Collis J, Manasseh R, Liovic P, Tho P, Ooi A, Petkovic-Duran K, et al. Cavitation microstreaming and stress fields created by microbubbles. Ultasonics. 2010; 50:273-279.

44. He CX, Tabata Y, Gao JQ. Non-viral gene delivery carrier and its three-dimensional transfection system. Int J Pharm. 2010; 386:232-242. [PubMed: 19922780]

45. Nakazawa Y, Huye LE, Dotti G, Foster AE, Vera JF, Manuri PR, et al. Optimization of the PiggyBac transposon system for the sustained genetic modification of human T-lymphocytes. J Immunother. 2009; 32:826-836. [PubMed: 19752751]

46. Palumbo G, Caruso M, Crescenzi E, Tecce MF, Roberti G, Colasanti A. Targeted gene transfer in eucaryotic cells by dye-assisted laser optoporation. J Photoch Photobio B. 1996; 36:41-46.

47. Pitsillides CM, Joe EK, Wei X, Anderson RR, Lin CP. Selective cell targeting with light-absorbing microparticles and nanoparticles. Biophys J. 2003; 84:4023-4032. [PubMed: 12770906]

48. Neumann JB, Brinkmann R. Microbubble dynamics around laser heated microparticles. SPIE Proc. 2003; 5142:82-87.

49. Baumgart J, Bintig W, Ngezahayo A, Willenbrock S, Murua Escobar H, Ertmer W, et al. Quantified femtosecond laser based opto-perforation of living GFSHR-17 and MTH53 a cells. Opt Express. 2008; 16:3021-3031. [PubMed: 18542388]

50. Kohli V, Elezzabi AY. Laser surgery of zebrafish (Danio rerio) embryos using femtosecond laser pulses: optimal parameters for exogenous material delivery, and the laser's effect on short- and long-term development. BMC Biotechnol. 2008; 8:7. [PubMed: 18230185]

51. Zeira E, Manevitch A, Khatchatouriants A, Pappo O, Hyam E, Darash-Yahana M, et al. Femtosecond infrared laser-an efficient and safe in vivo gene delivery system for prolonged expression. Mol Ther. 2003; 8:342-350. [PubMed: 12907157] 
52. Quinto-Su PA, Lai HH, Yoon HH, Sims CE, Allbritton NL, Venugopalan V. Examination of laser microbeam cell lysis in a PDMS microfluidic channel using time-resolved imaging. Lab Chip. 2008; 8:408-414. [PubMed: 18305858]

53. Dijkink R, Le Gac S, Nijhuis E, van den Berg A, Vermes I, Poot A, et al. Controlled cavitation-cell interaction: trans-membrane transport and viability studies. Phys Med Biol. 2008; 53:375-390. [PubMed: 18184993]

54. Arita Y, Torres-Mapa ML, Lee WM, Cizmar T, Campbell P, Gunn-Moore FJ, et al. Spatially optimized gene transfection by laser-induced breakdown of optically trapped nanoparticles. Appl Phys Lett. 2011; 98:093702.

55. Yao C, Qu X, Zhang Z, Huttmann G, Rahmanzadeh R. Influence of laser parameters on nanoparticle-induced membrane permeabilization. J Biomed Opt. 2009; 14:054034. [PubMed: 19895136]

56. Dolmetsch R, Xu K, Lewis R. Calcium oscillations increase the efficiency and specificity of gene expression. Nature. 1998; 392:933-936. [PubMed: 9582075] 
gold nanoparticle

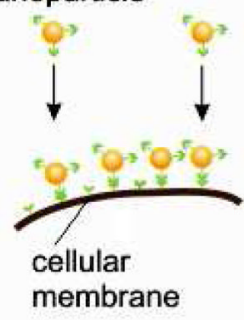

a

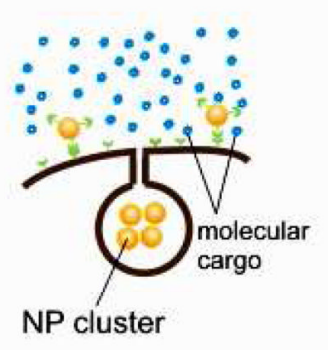

b

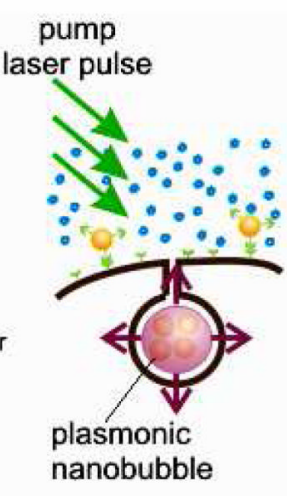

C

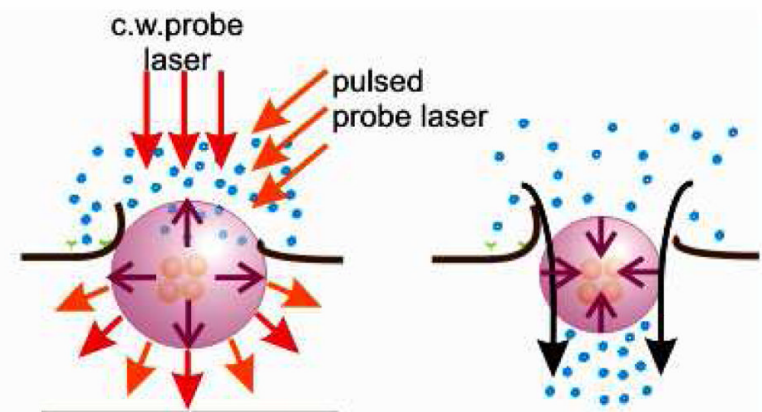

e

Figure 1.

Principle of nano-injection of extracellular molecular cargo. A: active targeting of gold NPs; b: formation of the NP clusters through the receptor-mediated endocytosis; c: a pump laser (green) pulse-induced generation of plasmonic nanobubble (PNB) around NP cluster; $d$ : formation of transient hole in cellular membrane by expanding PNB and PNB detection through optical scattering of probe lasers by PNB (red and orange); e: PNB collapse induces inboud jet that injects extracellular molecules into the cell. 

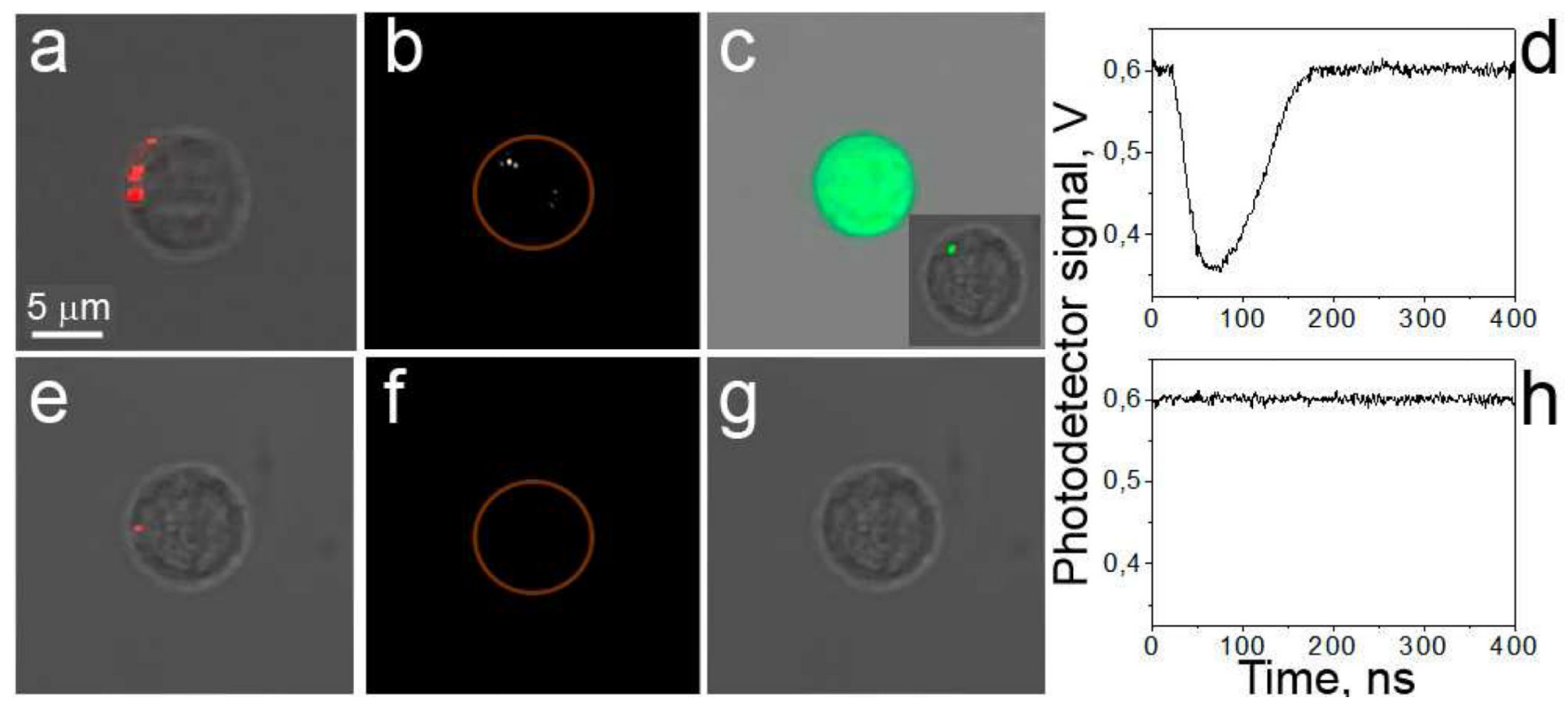

Figure 2.

Specificity of PNB mediated cargo delivery. CD3-positive (a-c) and -negative (e-g) cells in suspension. Images of target $(\mathrm{a}-\mathrm{c})$ and non-target $(\mathrm{e}-\mathrm{g})$ cells: a,e: confocal bright field and optical scattering images show NP clusters (red) in cells; b,f: time-resolved optical scattering images show bright PNB in target cell; c,g: confocal fluorescent and bright field images obtained after the PNB treatment show FITC-Dextran dye in target cell (the insert shows the initial delivery localization of dye within $10 \mathrm{~min}$ after PNB generation). Optical scattering time-responses show PNB-specific signal for target cell (d) and no PNB for non-target cell (h), the PNB lifetime is measured as duration of PNB-specific signals. 

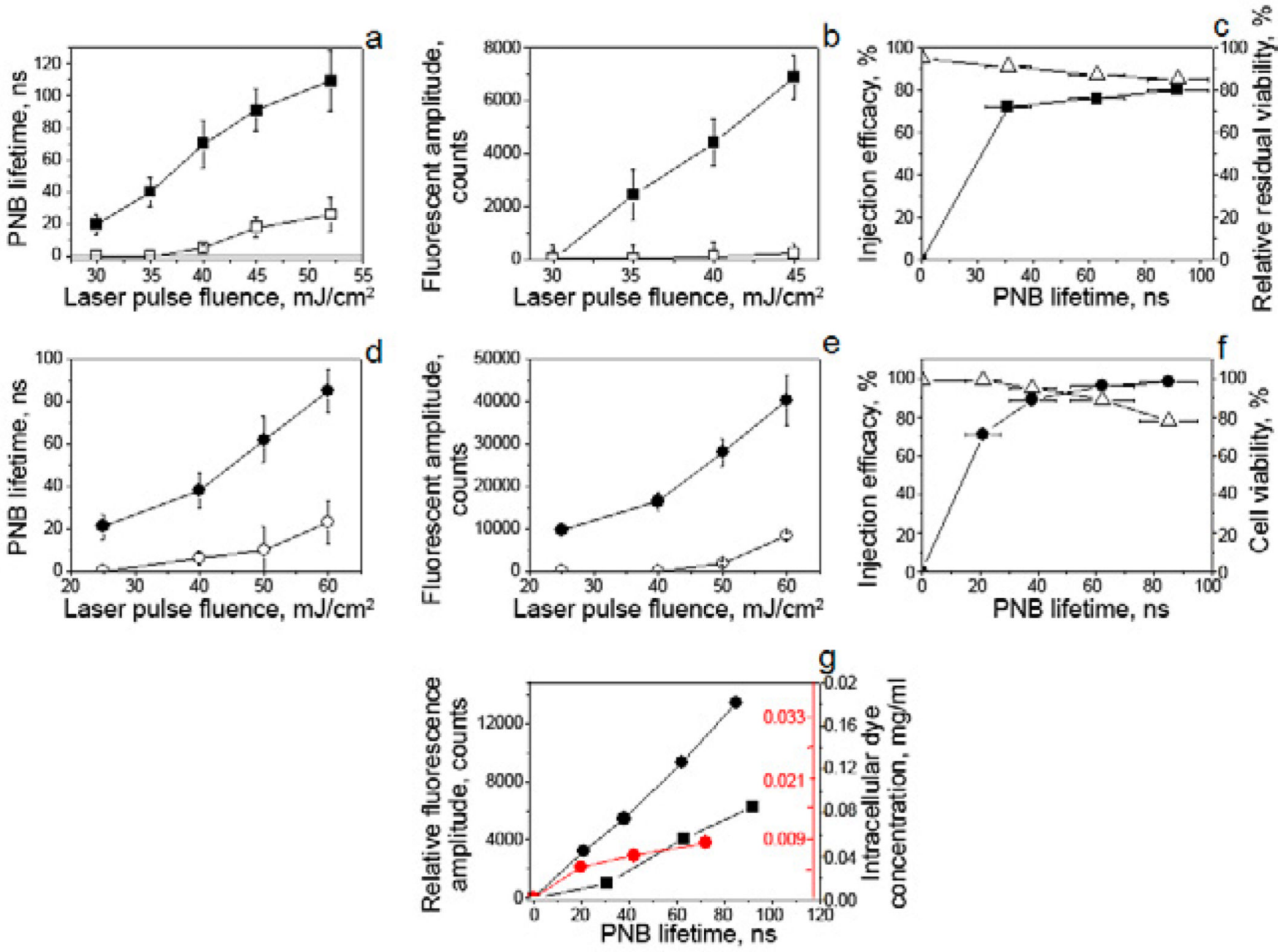

Figure 3.

Efficacy, selectivity and safety of nano-injection with PNBs: a-c: suspensions of CD3positive and -negative cells, d-f: culture of HN31/NOM9 adherent cells, a,d: PNB lifetime as function of the fluence of the pump (excitation) laser pulse for target (solid) and nontarget (hollow) cells. b,e: cell-averaged pixel image amplitude of dye-specific fluorescence $(2 \mathrm{~h}$ after PNB treatment) as function of the pump (excitation) laser pulse fluence for target (solid) and non-target (hollow) cells. c,f: Injection efficacy (solid symbols) and cell viability (hollow triangles) as function of the PNB lifetime; g: estimated cell-average intracellular concentration of the injected dye as function of the size (lifetime) of PNB and molecular weight of dye (black - $10 \mathrm{kDa}$, red - $2 \mathrm{MDa}$ ): squares - CD3-positive cells, dots - HN31 cells, the fluorescent image amplitudes were adjusted for HN31 cells to match the settings for imaging of CD3-positive cells. 

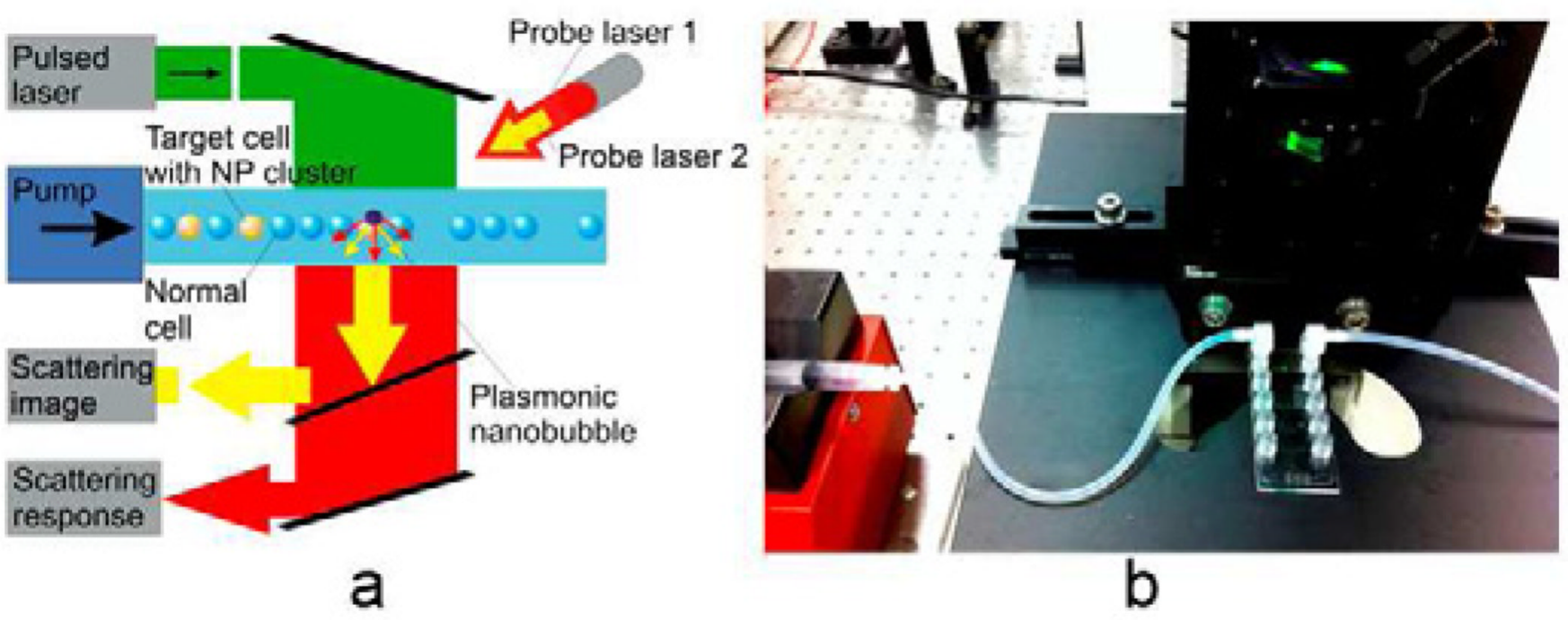

Figure 4.

Prototype of the flow PNB system. A: functional diagram; b: flow covette during laser irradiation of the suspension of cells. 

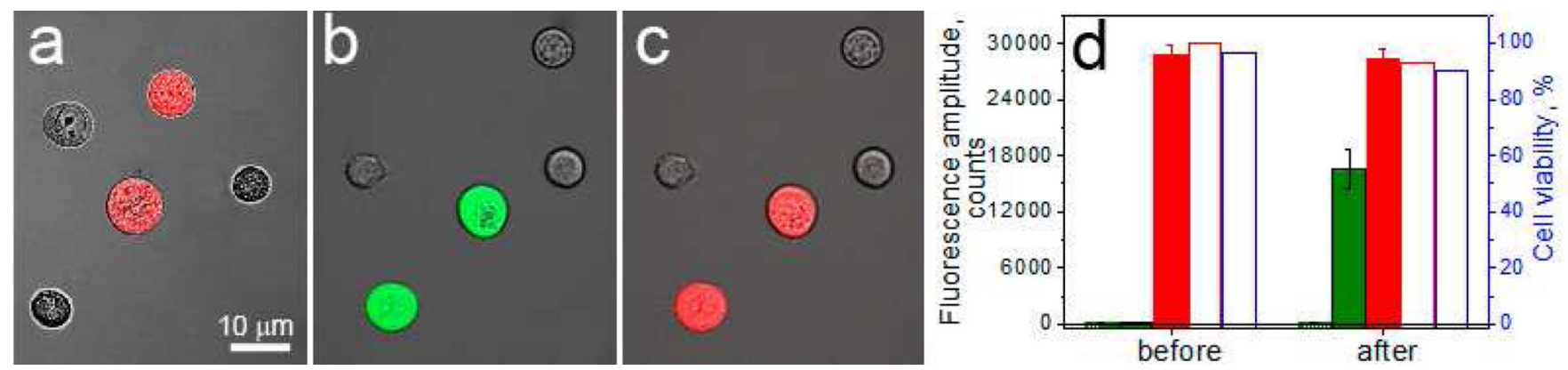

Figure 5.

Flow PNB treatment of suspension of mixed target, HN31 (Calcein Red-stained) and nontarget (no color) cells pre-targeted with NP-Panitumumab gold conjugates and treated in the flow PNB system in the presence of extracellular FITC-Dextran. A: Fluorescent image of Calcein Red shows target cells before treatment; B: Fluorescent image of FITC shows the Dextran delivered into the cells (green); C: Fluorescent image of the same cells as in B shows Calcein Red fluorescence in target cells $2 \mathrm{~h}$ after the treatment with PNBs; D: Diagram of cell parameters obtained before and after the treatment with PNBs: efficacy of the cargo delivery is shown for target (solid green bars) and non-target (hollow green bars) cells as cell-averaged pixel image amplitude of FITC-specific fluorescence (obtained in 10 min after the treatment); integrity of target cells is shown through cell-averaged pixel image amplitude of Calcein Red-specific fluorescence (solid red bars); the relative viability of target cells at $2 \mathrm{~h}$ after PNB treatment is shown by the concentration counts of Calcein Redpositive cells (hollow red bars, the level of their concentration before treatment is considered as 100\%) and by counts of Trypan Blue-negative target cells (hollow blue bars). 

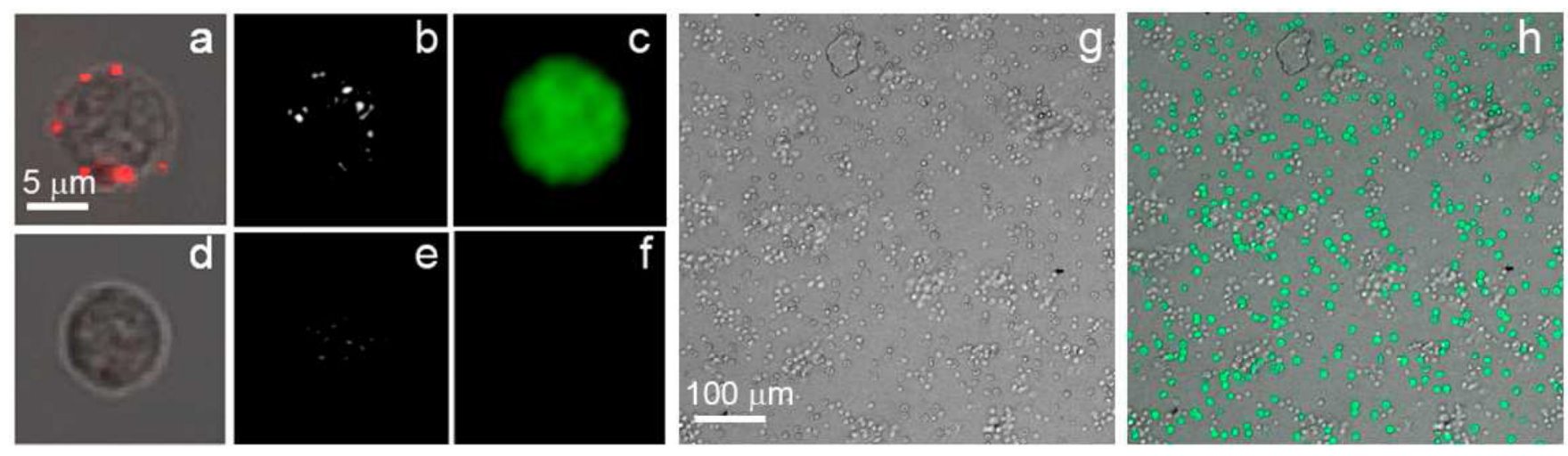

Figure 6.

Images of target (CD3-positive) (a-c) and non-target (CD3-negative) (d-f) cells. A,d: confocal bright field and optical scattering images show NP clusters (red) in cells; b,e: timeresolved optical scattering images show bright PNB in target cell; c,f: confocal fluorescent and bright field images obtained after the PNB treatment show GFP fluorescence in target cell after $72 \mathrm{~h}$. Images of the mixture of cells (CD3-positive/CD3-negative 50:50): g: bright field and h: GFP fluorescence after the PNB treatment (48 h). 

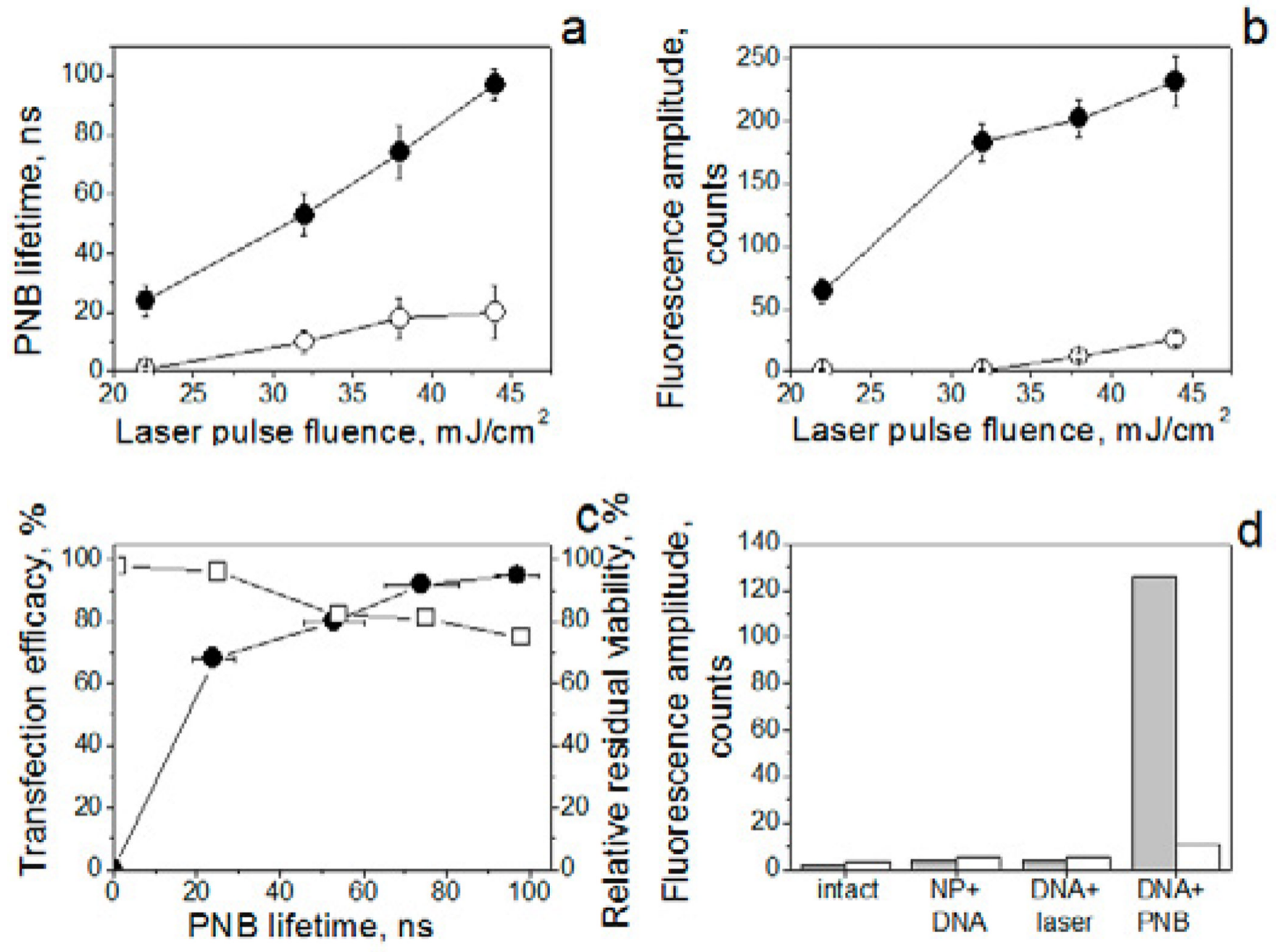

Figure 7.

PNB-based transfection of CD3-positive cells with plasmid DNA (pIRII-I-eGFP). A: PNB lifetime as function of optical excitation fluence for target (solid dots) and non-target (hollow dots) cells;b: pixel image amplitude of GFP intracellular fluorescence (measured as cell-averaged pixel image amplitude) for target and non-target cells; c: transfection efficacy (measured in $72 \mathrm{~h}$, solid dots) and residual viability index (hollow square) among PNBtreated target cells; d: pixel image amplitude of GFP-specific intracellular fluorescence (measured in $72 \mathrm{~h}$ as cell-averaged pixel image amplitude) for target (grey bar) and nontarget (white bar) cells after various treatments, NP+DNA - plasmid alone, DNA+laser plasmid and laser pulses were applied but cell were not treated with NPs, DNA+PNB - PNB injection method (laser pulse fluence $44 \mathrm{~mJ} / \mathrm{cm}^{2}$ ). 


\section{Table 1}

Gene transfection with PNB injection in flow system in heterogeneous cell suspension (Plasmid DNA: pIRIII-eGFP, $50 \mu \mathrm{g} / \mathrm{ml}$; laser treatment: $532 \mathrm{~nm}, 50 \mathrm{~mJ} / \mathrm{cm}^{2}$ ))

\begin{tabular}{|l|c|c|}
\hline Parameters & $\begin{array}{c}\text { Target cells } \\
\text { (CD3-positive) }\end{array}$ & $\begin{array}{c}\text { Non-target cells } \\
\text { (CD3-negative) }\end{array}$ \\
\hline PNB size (lifetime) ${ }^{*}, \mathrm{~ns}$ & $97 \pm 5$ & $20 \pm 9$ \\
\hline Efficacy as a level of transfected cells * $\%$ & $96 \pm 3$ & $10 \pm 2$ \\
\hline Cell viability as $R R V$ index after $72 \mathrm{~h} * \%$ & $75 \pm 8$ & $86 \pm 5$ \\
\hline
\end{tabular}

Averaged value \pm Standard Error of Mean 